\title{
Relationships Between Nutritional Condition of Adult Females and Relative Carrying Capacity for Rocky Mountain Elk
}

\author{
Jessica R. Piasecke ${ }^{1}$ and Louis C. Bender ${ }^{2}$ \\ Authors are ${ }^{1}$ Research Assistant, Department of Fishery and Wildlife Sciences, New Mexico State University, Las Cruces, NM 88003, USA and ${ }^{2}$ Research \\ Wildlife Biologist, US Geological Survey, New Mexico Cooperative Fish and Wildlife Research Unit, PO Box 30003 MSC 4901, Las Cruces,
} NM 88003, USA.

\begin{abstract}
Lactation can have significant costs to individual and population-level productivity because of the high energetic demands it places on dams. Because the difference in condition between lactating and dry Rocky Mountain elk (Cervus elaphus nelsoni) cows tends to disappear as nutritional quality rises, the magnitude of that difference could be used to relate condition to habitat quality or the capability of habitats to support elk. We therefore compared nutritional condition of $\geq 2.5$-yr-old lactating and dry cows from six free-ranging Rocky Mountain elk populations throughout the United States. Our goal was to quantify differential accrual of body fat (BF) reserves to determine whether the condition of dry and lactating cows could be used to define relevant management thresholds of habitat quality (i.e., relative carrying capacity) and consequently potential performance of elk populations. Levels of BF that lactating cows were able to accrue in autumn and the proportional difference in BF between dry and lactating cows in autumn were related $\left(F_{1-2,10} \geq 16.2, P<0.001\right)$. Models indicated that elk experienced no negative effects of reproduction on condition when lactating cows were able to accrue $\geq 13.7 \% \mathrm{BF}$ in autumn. When lactating cows are accruing $\leq 7.9 \% \mathrm{BF}$, elk are in a nutritionally stressed condition, which may be limiting population performance. Using the logistic model to predict relative proximity to ecological carrying capacity (ECC), our population-years ranged from 3-97\% of ECC and proportion of the population lactating (an index of calf survival) was negatively related to proportion of ECC. Results indicate that the proportional difference in accrual of BF between lactating and dry cows can provide a sensitive index to where elk populations reside relative to the quality of their range.
\end{abstract}

\section{Resumen}

La lactación tiene un costo significativo en la productividad, tanto a nivel individual como a nivel de la población, debido a la alta demanda energética que se impone en las hembras. Debido a que la diferencia en la condición corporal entre las hembras alce lactantes y secas (Cervus elaphus nelsoni) tiende a desaparecer conforme la calidad nutricional aumenta, la magnitud de esta diferencias podría utilizarse para relacionar la condición con la calidad del hábitat o la habilidad del hábitat para el sostenimiento de los alces. Por lo tanto, comparamos la condición nutricional de hembras lactantes mayores de 2.5 años en seis poblaciones de alces pastoreando en las montañas rocallosas en los Estados Unidos. Nuestra meta era cuantificar las diferencias de las reservas de la grasa corporal (BF) para determinar ya sea que la condición de las hembras lactantes o secas podrían ser usadas para definir un punto de partida apropiado para el manejo de la calidad del hábitat (ej. Relacionado con la capacidad de carga) y por lo tanto la posibilidad potencial del rendimiento de la población de alces. Los niveles de la grasa corporal que fue posible acumular en las hembras durante el otoño y la diferencia proporcional en la grasa corporal entre las hembras lactantes y secas se relacionó con $\left(F_{1-2,10} \geq 16.2\right.$; $P<0.001)$. Estos modelos indican que los alces no pasan por efectos negativos en la reproducción y en la condición corporal cuando las hembras lactantes acumularon $\geq 13.7 \%$ de grasa corporal durante el verano. Cuando las hembras lactantes acumularon $\leq 7.9 \%$ de grasa corporal, los alces presentan una condición de estrés nutricional que quizá limita el rendimiento de la población. Utilizando los modelos logísticos para predecir la cercanía relativa la capacidad de carga ecológica (ECC), nuestra población-años tiene un rango de 3-97\% de ECC y la proporción de la población lactante un índice de la sobrevivencia de los recién nacidos se relaciono negativamente a la proporción de ECC. Estos resultados indican que la población de alces en pastoreo experimenta un amplio rango en la calidad del hábitat en los E.U. y que la diferencia proporcional en la acumulación de grasa corporal entre las hembras lactantes y secas puede proporcionar un índice confiable acerca de las poblaciones de alces en relación a la calidad del pastizal.

Key Words: body fat, Cervus elaphus nelsoni, ecological carrying capacity, habitat, reproduction

Funding for and cooperation with the various aspects of this project were provided by the US Geological Survey, New Mexico Dept of Game and Fish, National Park Service (Chaco Culture National Historic Park and Rocky Mountain National Park), US Department of Defense (Fort Riley), Washington Dept of Fish and Wildlife, Rocky Mountain Elk Foundation, Upper Skagit Tribe, US Forest Service (Lincoln National Forest), Crown Pacific, National Council for Air and Stream Improvement, and the New Mexico State University Agriculture Experiment Station.

Correspondence: Louis C. Bender, US Geological Survey, New Mexico Cooperative Fish and Wildlife Research Unit, PO Box 30003 MSC 4901, Las Cruces, NM 88003, USA. Email: Ibender@nmsu.edu

Manuscript received 4 March 2007; manuscript accepted 16 November 2008.

\section{INTRODUCTION}

Estimating capability of habitats to support elk (Cervus elaphus) or other large wild herbivores (i.e., carrying capacity) is challenging because differing digestive and foraging strategies among species (Hofmann 1989) and foraging constraints faced by wild herbivores, particularly much higher dietary requirements relative to domestic livestock and consequently greater search times, etc. (Wickstrom et al. 1984; Gray and Servello 1995; Cook 2002), preclude use of traditional range manage- 
ment techniques based solely on forage quantity such as animal unit equivalents (Holechek et al. 2004). Energy needs for late gestation and lactation in elk are greater than those for other life processes (Trainer 1969; Cook 2002), and these high energy requirements result in lactating cows that are in predictably poorer condition than cows that are not lactating (hereafter, dry; Clutton-Brock et al. 1982; Hudson et al. 2002; LandeteCastillejos et al. 2003; Cook et al. 2004). Given no nutritional limitations, however, penned lactating elk were able to achieve levels of ingesta-free body fat (BF) in autumn equivalent to dry cows because they had sufficient nutrients to both maintain high condition and produce milk (Cook et al. 2004). Because the difference in condition between lactating and dry cows tends to disappear as nutritional quality rises (Cook et al. 2004; Piasecke 2006), the magnitude of that difference could be used to relate condition to habitat quality or the capability of habitats to support elk.

Whether a result of increased population density or densityindependent declines in habitat quality, nutritional limitations due to decreased resource capture affect elk in a predictable process, i.e., first through decreased individual condition, followed by declines in juvenile fecundity, juvenile survival, adult fecundity, and, last, adult survival (Hanks 1981; Gaillard et al. 2000). Because differences in condition between lactating and dry cows vary with absolute levels of condition attained and thus habitat quality (i.e., resource capture), these differences could also be used as a relative index of proximity of an elk population to ecological carrying capacity (ECC; Caughley 1979) irrespective of the type of habitat occupied. A population is at ECC or "food-limited" carrying capacity when a given habitat in general will not support any further population growth, i.e., population productivity will balance population mortality because of declines in productivity and increases in mortality driven by decreasing per capita resource capture (Caughley 1979; Gaillard et al. 2000; Eberhardt 2002).

Proportional differences between lactating and dry cows could index this relationship because mean condition of elk in any population would fall somewhere along a continuum from too poor to allow successful gestation and lactation (i.e., production of a calf) to levels when the costs of reproduction result in no nutritional limitation on cows (i.e., where lactating cows achieve similar condition as dry cows; Piasecke 2006). When habitat quality is sufficient that lactating and dry cows do not differ in mean condition, the population is in effect experiencing no relevant resource stress and is near maximally distant from ECC. Conversely, when habitat quality is severely limiting, differences in condition between lactating and dry cows would be greatest, and a population at or above ECC (i.e., approximately $100 \%$ of ECC). Although factors other than nutrition (such as disturbance, disease, etc.) can influence condition of free-ranging ungulates, these factors tend to be most relevant when populations are malnourished (Sinclair 1977; Kistner et al. 1982). Consequently, nutrition during the spring-autumn period has the predominant effect on autumn condition of elk and consequently most measures of productivity and survival (Cook et al. 2004; Bender et al. 2006, 2008).

Identifying important thresholds relative to the ability of habitats to provide for the well-being of elk, or determining proximity of an elk population to ECC, is useful because stakeholders often have strongly differing views on what an optimal population size or density is for elk. Consequently, disagreements as to whether or not a population is above "carrying capacity" ensue, with many different sociological carrying capacities (for example, maximum sustained yield, forage allocation issues, deleterious impacts to desired conditions of plant communities, etc.) being vehemently argued (Carpenter 2000), usually in the context of ECC (Caughley 1979). Moreover, balancing elk populations with their habitat requires managers to define where elk populations are with respect to the capability of their habitats to provide for their life requisites, i.e., relative to ECC. Hence our goals were to 1) measure nutritional condition of lactating and dry Rocky Mountain elk (Cervus elaphus nelsoni; hereafter, elk) in various free-ranging populations throughout the United States, 2) model the relationship between condition and cost of lactation, and 3) use relationships found to develop a model relating habitat quality to the cost of lactation, and thus ECC.

\section{METHODS}

\section{Study Areas}

Our study populations occurred throughout the United States and experienced a variety of habitat and population conditions (Fig. 1; Table 1). These include Southwestern desert grassland/ shrubland (Chaco Culture National Historic Park [CCNHP], located in northwestern New Mexico at approximately lat $36^{\circ} 00^{\prime} \mathrm{N}$, long $108^{\circ} 00^{\prime} \mathrm{W}$ ); temperate tallgrass prairie (Fort Riley, located in the Flint Hills of northeastern Kansas at approximately lat $39^{\circ} 06^{\prime} \mathrm{N}$, long $\left.96^{\circ} 48^{\prime} \mathrm{W}\right)$; high elevation montane conifer-grassland mosaics (Rocky Mountain National Park [RMNP], located in the Rocky Mountain Front Range of north-central Colorado at approximately lat $40^{\circ} 23^{\prime} \mathrm{N}$, long $105^{\circ} 38^{\prime} \mathrm{W}$, which contained two subpopulations of elk, Moraine Park [Moraine] and Horseshoe Park [Horseshoe] that we analyzed separately following Bender and Cook [2005]); high-elevation Southwestern montane conifer and oak woodland (Lincoln National Forest [LNF], located in the Sacramento Mountains of southcentral New Mexico at approximately lat $32^{\circ} 51^{\prime} \mathrm{N}$, long $\left.105^{\circ} 44^{\prime} \mathrm{W}\right)$; and inland northern temperate conifer rainforest (Nooksack, located in northwestern Wash-

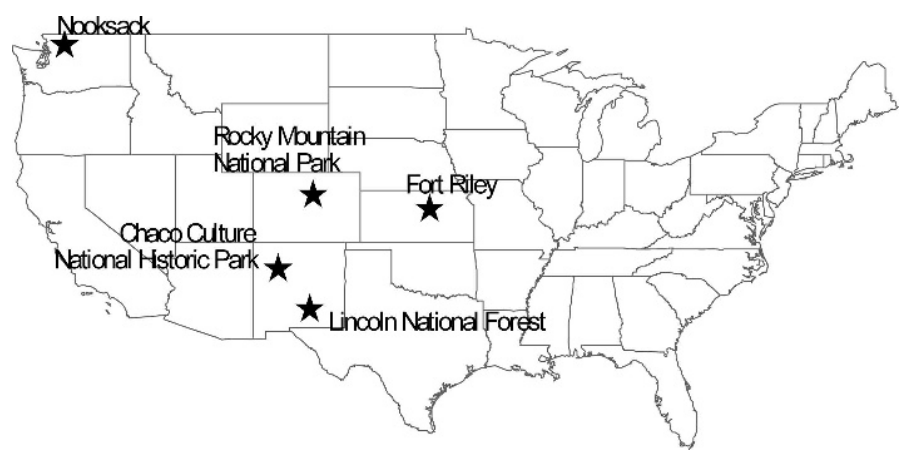

Figure 1. Locations of study populations of Rocky Mountain elk throughout the United States. 
Table 1. Mean July high and January low temperatures, annual precipitation, range of annual precipitation over study years, percentage of precipitation that fell during the late-gestation and lactation seasons of elk (May-September), elk density, and migratory status of six study populations of Rocky Mountain elk from across the western United States.

\begin{tabular}{|c|c|c|c|c|c|c|c|}
\hline \multirow[b]{2}{*}{ Area $^{1}$} & \multicolumn{2}{|c|}{ Temperature $\left({ }^{\circ} \mathrm{C}\right)$} & \multicolumn{3}{|c|}{ Precipitation $(\mathrm{cm})$} & \multirow[b]{2}{*}{ Density $\left(\right.$ elk $\left.\cdot \mathrm{km}^{-2}\right)$} & \multirow[b]{2}{*}{ Migrate? } \\
\hline & July & January & Annual & Range $^{2}$ & May-September & & \\
\hline CCNHP & 32.2 & -10.6 & 23 & -0.16 to +0.02 & 59 & 0.1 & No \\
\hline Fort Riley & 32.2 & -9.4 & 87 & -0.23 to +0.06 & 61 & 2.7 & No \\
\hline RMNP $^{3}$ & 26.1 & -7.8 & 35 & -0.30 & 64 & 1.3 & Yes \\
\hline LNF & 21.7 & -8.3 & 67 & -0.34 to -0.06 & 60 & 0.7 & No \\
\hline Nooksack & 23.9 & 0.0 & 180 & -0.33 to -0.02 & 19 & 0.2 & Yes \\
\hline
\end{tabular}

${ }^{1}$ CCNHP indicates Chaco Culture National Historic Park, New Mexico; LNF, Lincoln National Forest, New Mexico; RMNP, Rocky Mountain National Park, Colorado.

${ }^{2}$ Range $=$ standard normal variate of total annual precipitation in years of study calculated as (precipitation ${ }_{y}-\bar{x}$ precipitation) $/ \bar{x}$ precipitation.

${ }^{3}$ RMNP consists of two study populations, Moraine and Horseshoe Park.

ington state at approximately lat $48^{\circ} 34^{\prime} \mathrm{N}$, long $121^{\circ} 55^{\prime} \mathrm{W}$; Table 1). See Piasecke (2006) for more detailed descriptions of study sites.

\section{Capture and Condition}

We captured 201 adult ( $\geq 2.5$ yr old) cow elk in autumn (lateOctober-mid-November, at the population's approximate peak of fat accretion based upon plant phenology) from a helicopter or from vehicles on roads in RMNP, immobilized elk with carfentanil citrate and xylazine hydrochloride $(3.6 \mathrm{mg}$ carfentanil citrate $+100 \mathrm{mg}$ xylazine $\cdot \mathrm{elk}^{-1}$ ), and blindfolded elk to calm the animals and prevent eye injury. We also treated each elk with penicillin, vitamin E/selenium, vitamin B, and an eightway Clostridium bactrain to alleviate the physiological stress and trauma of capture. We determined lactation status by checking the udder for milk, which indicated survival of a calf to within $\leq 3-11 \mathrm{~d}$ of capture (Bender et al. 2002). We antagonized immobilants with $300 \mathrm{mg}$ naltrexone (one-half intravenous and one-half subcutaneous) and $800 \mathrm{mg}$ tolazoline (delivered intravenously). We had $\geq 2 \mathrm{yr}$ of data from each study population except for Moraine and Horseshoe in RMNP (1 yr for each site; $n=15$ and 14, respectively; Table 2).
Annual sample sizes were as follows: CCNHP (4 yr; $n=7-20)$, LNF (3 yr; $n=16-24)$, Nooksack (3 yr; $n=9-13)$, and Fort Riley (2 yr; $n=8-11$; Table 2).

We determined a rump body condition score (rBCS) by palpation of the soft tissue of the rump near the base of the tail (Cook 2000). We palpated the sacral ridge and sacro-sciatic ligament, measuring how much of the sacral ridge was discernible above the subcutaneous fat layer and how much of the sacro-sciatic ligament had been exposed by catabolism of subcutaneous fat and lean tissue. We scored results of rBCS measures from standards of the body condition score, which ranged from 1 (emaciated) to 5 (obese) in intervals of 0.25 (Cook 2000).

We used a SonoVet 2000 ultrasound (Medison, Seoul, South Korea) with a $5-\mathrm{mHz}$ probe to measure subcutaneous fat thickness (MAXFAT) along a straight line midway between the spine, at its closest point to the coxal tuber (hip bone) and the ischial tuber (pin bone; Cook 2000). The ultrasound provided a cross-sectional view of skin, fat, and muscle at this site, and the thickest part of the fat layer was measured in centimeters. We estimated total BF by combining rBCS and MAXFAT into an index (rLIVINDEX), where

Table 2. Mean (SE) maximum rump subcutaneous fat thickness (MAXFAT), rump body condition score (rBCS), and ingesta-free body fat (BF) and sample sizes for $\geq 2.5$-yr-old Rocky Mountain cow elk for pooled lactating and dry cows in autumn among different population-years.

\begin{tabular}{|c|c|c|c|c|c|c|}
\hline Location $^{1}$ & MAXFAT & $n$ & rBCS & $n$ & $\mathrm{BF}(\%)$ & $n$ \\
\hline CCNHP 2003 & $2.4(0.3)$ & 7 & $3.4(0.1)$ & 7 & $13.3(0.6)$ & 7 \\
\hline CCNHP 2004 & $2.0(0.1)$ & 16 & $3.1(0.1)$ & 16 & $12.0(0.4)$ & 16 \\
\hline CCNHP 2005 & $0.3(0.2)$ & 15 & $2.5(0.1)$ & 15 & $6.2(0.6)$ & 15 \\
\hline CCNHP 2006 & $1.3(0.2)$ & 20 & $3.2(0.2)$ & 20 & $9.7(0.6)$ & 20 \\
\hline Fort Riley 2003 & $2.1(0.3)$ & 9 & $3.5(0.3)$ & 11 & $11.5(1.3)$ & 11 \\
\hline Fort Riley 2005 & $2.1(0.4)$ & 8 & $3.2(0.2)$ & 8 & $11.6(1.2)$ & 8 \\
\hline Horseshoe & $2.3(0.4)$ & 11 & $3.7(0.2)$ & 14 & $12.8(1.0)$ & 14 \\
\hline Moraine & $1.5(0.2)$ & 12 & $3.1(0.1)$ & 15 & $9.7(0.7)$ & 15 \\
\hline LNF 2003 & $2.3(0.2)$ & 18 & $3.2(0.1)$ & 21 & $11.5(0.7)$ & 21 \\
\hline LNF 2004 & $2.7(0.1)$ & 12 & $3.7(0.1)$ & 16 & $13.1(0.5)$ & 16 \\
\hline LNF 2005 & $1.4(0.2)$ & 24 & $3.2(0.1)$ & 24 & $10.1(0.6)$ & 24 \\
\hline Nooksack 2000 & $2.5(0.3)$ & 11 & $3.6(0.2)$ & 12 & $13.0(0.8)$ & 12 \\
\hline Nooksack 2001 & $2.1(0.3)$ & 13 & $3.6(0.3)$ & 13 & $12.2(1.2)$ & 13 \\
\hline Nooksack 2002 & $2.4(0.2)$ & 7 & $4.1(0.1)$ & 9 & $14.0(0.4)$ & 9 \\
\hline
\end{tabular}

${ }^{1}$ CCNHP indicates Chaco Culture National Historic Park, New Mexico; LNF, Lincoln National Forest, New Mexico. 


$$
\text { rLIVINDEX }=\text { rBCS }
$$

when MAXFAT $<0.3 \mathrm{~cm}$ (i.e., less than measurement error of the ultrasound); and

$$
\text { rLIVINDEX }=(\text { MAXFAT }-0.3)+\text { rBCS }
$$

when MAXFAT $\geq 0.3 \mathrm{~cm}$ (Cook et al. 2001a). We then calculated percent BF from rLIVINDEX using

$$
\begin{aligned}
\mathrm{BF}= & -7.1527185+7.323081 x-0.98980456 x^{2} \\
& +0.057445567 x^{3}\left(R^{2}=0.89\right)
\end{aligned}
$$

where $x=$ rLIVINDEX (Cook et al. 2001a). If no MAXFAT figure was available (usually because of ultrasound failure), we calculated BF from rBCS only (Cook et al. 2001a) using

$$
\mathrm{BF}=4.478 \cdot \mathrm{rBCS}-4.618\left(R^{2}=0.86\right) .
$$

We used the polynomial equations to estimate BF whenever possible because it most accurately models pattern of BF catabolism in elk (Cook 2000; Cook et al. 2001a, 2001b).

\section{Data Analysis}

We tested for differences in means of rBCS, MAXFAT, and BF inclusive of lactational status among population-years using the Kruskal-Wallis analysis of variance (Zar 1996). We used $\alpha=0.10$ for all statistical comparisons. To determine the cost of lactation on a cow's ability to accrue BF among populations (i.e., habitats), the mean proportional differences in BF between lactating and dry cows, i.e.,

$$
\mathrm{BF}_{\mathrm{dry}}-\mathrm{BF}_{\text {lactating_cows }} / \mathrm{BF}_{\text {lactating_cows }}
$$

in autumn by population-year were regressed against mean autumn BF of lactators. We used BF because fat is closely tied to nutrition, is useful over the entire range of possible condition, and is a sensitive indicator of overall habitat quality (Cook et al. 2001b; Cook 2002). We related mean differences to BF of lactating cows to standardize the index against the most nutritionally stressed component of the population, and thus make the index most sensitive to changes in habitat quality (Clutton-Brock et al. 1982, Cook et al. 2004, Piasecke 2006) and robust to differences in habitats and densities of elk. Moreover, all published criteria for wild elk performance (Cook et al. 2004) are stated in terms of BF of lactating cows, thus allowing direct comparisons between model predictions, thresholds of productivity, and nutritional needs of elk. We used $R^{2}$ (a difference of $>0.10$ was considered biologically relevant) and Akaike's information criterion (AIC; differences of $>2$ were considered biologically relevant; Burnham and Anderson 1998; Eberhardt 2003) to select the best model among linear, polynomial, and logistic (Bayliss and Choquenot 2003 ) candidates. We identified the $x$-intercepts of the best models, which would indicate the level of BF at which no resource stress was occurring, i.e., when a population could be considered to be maximally distant from ECC (hereafter, at approximately $0 \%$ of ECC).

To fit logistic models, we used the two intercepts from the linear or polynomial models and fit the model

$$
y=y_{\max } \cdot\left[1-\left(x / x_{\max }\right)^{\mathrm{Z}}\right]
$$

where $Z$ is a term that indicates the intensity of resource stress (Bayliss and Choquenot 2003). We varied $x_{\max }$ and $y_{\max }$ incrementally from intercepts identified from the linear and polynomial models above to find the best combination by maximizing model $R^{2}$ and AIC. So that this relationship could be used as an estimator of ECC, we then rescaled the range of the dependent variable from $y=0.0$ to $y=1.0$ so that percentage of $\mathrm{BF}$ of lactating cows could be used to predict relative proximity to ECC. Lastly, we used linear regression to relate the proportion of adult cows lactating in each population (an index of calf survival until approximately 6 mo of age; Bender et al. 2002) to predicted proportion of ECC to see whether population productivity was related to proportion of ECC or relative elk condition.

\section{RESULTS}

We captured and assessed for condition a total of 201 Rocky Mountain elk. Multiple captures were performed at most study sites for a total of 14 population-years for analysis. Body condition varied markedly among and within populations (Table 2$)$ based on BF $\left(H_{13}=67.4 ; \quad P<0.001\right)$, rBCS $\left(H_{13}=83.2 ; \quad P<0.001\right), \quad$ and MAXFAT $\quad\left(H_{13}=53.5\right.$; $P<0.001)$. Data from Fort Riley in 2005 could not be included in $\mathrm{BF}$ modeling because all cows were lactating.

Logistic $\left(F_{1,12}=147.7, P<0.001, R^{2}=0.69\right)$ and polynomial $\left(F_{2,10}=16.2, P<0.001, R^{2}=0.76\right)$ models were statistically indistinguishable in selection criteria and provided the best fit (Table 3) in predicting the relationships between proportional differences in BF of lactating and dry cows as a function of BF levels of lactating cows in autumn. Because the polynomial model peaked and declined as elk condition declined (Fig. 2A), suggesting that condition costs of cows due to lactation decrease as elk approach ECC, we selected the logistic model as our preferred model although we use both to identify critical thresholds. The logistic relationship between the proportional differences in BF in autumn between dry and lactating elk and BF of lactators was

$$
y=0.51 \cdot\left[1-(x / 13.7)^{3.863}\right]
$$

(Fig. 2A), where $x=$ mean BF of lactating cows and $y=$ proportional difference in BF between lactating and dry cows in autumn, at the approximate peak of fat accretion. The logistic relationship indicated that the difference between lactating and dry cows disappeared when autumn BF levels of lactating cows reached $13.7 \%$. For both logistic and polynomial models, differences in BF 
levels of lactating and dry cows reached their approximate peak when lactating cows were able to accrue $\leq 7.9 \% \mathrm{BF}$ (Fig. 2A).

When rescaled from $y=0$ to $y=1$, the logistic model indicated that an incremental change in percentage of ECC had a greater effect on BF levels the closer a population was to ECC (Fig. 2B), and that the differences in BF attainable by lactating and dry cows peaked at approximately $7.9 \% \mathrm{BF}$ accrued by lactators (Fig. 2B; see Discussion). Applying the model to our population-years, proportion of ECC ranged from $3 \%$ (Nooksack 2002) to 97\% (CCNHP 2005; Table 4). Among our elk population-years, proportion of elk lactating was negatively related to proportion of ECC $(r=-0.51$, $\left.F_{1,11}=3.8, P=0.078\right)$.

\section{DISCUSSION}

We found that difference in $\mathrm{BF}$ accrual between dry and lactating elk in late autumn decreased as nutritional condition increased (Fig. 2A), similar to other studies of elk (Cook et al. 2004) and bighorn sheep (Ovis canadensis; Festa-Bianchet et al. 1998). Further, because this relationship was predictable, BF accrued by lactating adult cows can be used to directly relate an elk population to the nutritional quality of its habitat and hence ECC. At ECC, individuals would be experiencing nearmaximum nutritional stress and consequently most would be unable to reproduce (Caughley 1979; Gaillard et al. 2000; Eberhardt 2002). Conversely, when at a small proportion of ECC, there is negligible nutritional limitation occurring, so there should be no difference in BF between lactating and dry cows despite the high energetic requirements of lactation and hence no constraints on reproduction. We found that this occurred when lactating cows in autumn were able to accrue approximately $14 \% \mathrm{BF}$, indicating that habitat ceases to be a limiting factor on elk performance when resources are sufficient to allow lactating cows to achieve this level of condition (Fig. 2B). This, in effect, defines when a population is experiencing no relevant resource stress and is maximally distant from ECC.

Cook et al. (2004) found that individual lactating elk were able to accrue $\geq 17 \%$ BF in penned studies. We similarly found that some individual free-ranging elk achieved $\mathrm{BF}$ levels greater than $13.7 \%(10.5 \%$ of lactators [maximum $=15.9 \% \mathrm{BF}$ ). However, maximum BF levels attainable say nothing about when habitat quality ceases to have an inhibitory effect on elk performance, whereas the point when lactational costs are no longer manifested does, because lactation is the greatest resource challenge faced by elk (Trainer 1969). Our modeled
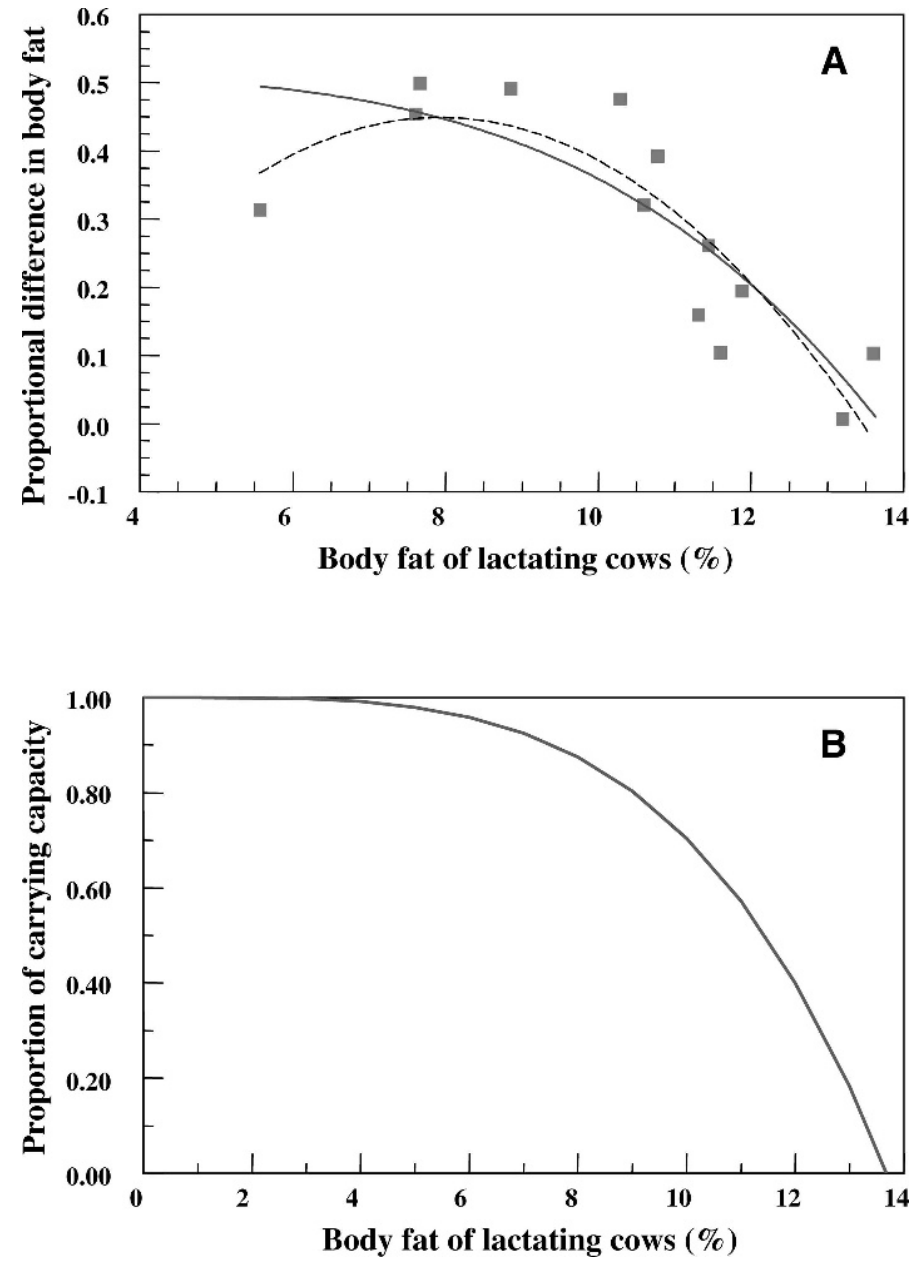

Figure 2. A, Logistic $\left(y=0.51 \cdot\left[1-\{x / 13.7\}^{3.863}\right] ; \quad F_{1,12}=147.7\right.$, $P<0.001$; solid line) and polynomial $(y=-0.475+0.233 \cdot x-$ $0.015 \cdot x^{2} ; F_{2,10}=16.2, P<0.001$; dashed line) models of proportional difference in body fat (BF) between lactating and dry cows as a function of mean BF of lactating cow in autumn from various free-ranging Rocky Mountain elk populations throughout the United States. B, Logistic model of proportion of ecological carrying capacity (ECC; $y=1-[x]$ $13.7]^{3.863}$ ) as related to mean BF levels of lactating $\geq 2.5$-yr-old cows in autumn from various Rocky Mountain elk populations throughout the United States.

ECC relationship also indicated that reproductive costs as indexed by lowered accrual of $\mathrm{BF}$ were greatest when condition of lactators dropped below approximately $7.9 \% \mathrm{BF}$, indicating that strong nutritional stress and, consequently, declines in individual and population-level performance would likely be acting on elk populations at or below this threshold condition

Table 3. Parameters of linear, second-order polynomial, and logistic models relating percent ingesta-free body fat of lactating $\geq 2.5$-yr-old Rocky Mountain cow elk in autumn to the proportional difference in body fat between dry and lactating cows in autumn.

\begin{tabular}{|c|c|c|c|c|c|c|c|c|c|c|c|c|c|}
\hline \multirow[b]{2}{*}{ Model } & \multicolumn{4}{|c|}{ Model selection criteria ${ }^{1}$} & \multicolumn{9}{|c|}{ Parameter estimates } \\
\hline & $F$ & $P$ & $R^{2}$ & $\Delta \mathrm{AlC}_{\mathrm{c}}$ & $y$-int & SE & $x$ & SE & $x^{2}$ & SE & $x$-int & $Z$ & SE \\
\hline Polynomial & 16.2 & $<0.001$ & 0.76 & 0 & -0.475 & 0.416 & 0.233 & 0.088 & -0.015 & 0.005 & 13.5 & - & - \\
\hline Linear & 11.7 & 0.006 & 0.51 & 7.4 & 0.823 & 0.149 & -0.051 & 0.015 & - & - & 16.0 & - & - \\
\hline Logistic & 147.7 & $<0.001$ & 0.69 & 0.05 & 0.51 & - & - & - & - & - & 13.7 & 3.863 & 0.684 \\
\hline
\end{tabular}

${ }^{1} \mathrm{AlC}_{\mathrm{c}}$ indicates Akaike information criterion corrected for small sample sizes. 
Table 4. Percentage of ecological carrying capacity (\%ECC) of populations of Rocky Mountain elk annually by study site as estimated from logistic model.

\begin{tabular}{lcc}
\hline \multicolumn{1}{c}{ Population } & Year & \%ECC \\
\hline CCNHP $^{1}$ & 2003 & 13 \\
CCNHP & 2004 & 52 \\
CCNHP & 2005 & 97 \\
CCNHP & 2006 & 92 \\
Fort Riley & 2003 & 47 \\
Fort Riley & 2005 & 48 \\
Horseshoe & 2001 & 63 \\
Moraine & 2001 & 89 \\
Lincoln National Forest & 2003 & 60 \\
Lincoln National Forest & 2004 & 50 \\
Lincoln National Forest & 2005 & 82 \\
Nooksack & 2000 & 42 \\
Nooksack & 2001 & 67 \\
Nooksack & 2002 & 3 \\
\hline
\end{tabular}

${ }^{1}$ CCNHP indicates Chaco Culture National Historic Park, New Mexico.

(Figs. 2A and 2B). Research on pronghorn (Antilocapra americana) has postulated $2 \% \mathrm{BF}$ as the "death threshold" from which ungulates cannot physiologically recover (Depperschmidt et al. 1987). This supports our modeled relationships indicating an elk population being essentially at ECC when lactators accrue $<4 \% \mathrm{BF}$, which would equate to $>99 \%$ of ECC (Fig. 2B).

However, we are unsure whether the logistic or polynomial model most accurately reflects differences in BF between lactating and dry cows below the approximately $7.9 \% \mathrm{BF}$ threshold. Although the polynomial model indicates that proportional differences decline as lactators accrue $<7.3 \%$ $\mathrm{BF}$, which is seemingly less biologically reasonable than the plateau seen in the logistic model (Fig. 2A), it is possible that differences may converge under extreme nutritional stress. For example, as diet quality declines such that lactating elk are able to accrue very little $\mathrm{BF}$, diet qualities are likely so low that dry cows would similarly be unable to accrue high levels of BF and may differ little from the few cows that successfully raise a calf. This concern is relevant, because if proportional differences in condition between lactating and dry cows decrease at very low levels of condition, the elevation (plateau) of the best approximating logistic model would also decrease, resulting in a more gradual approach to ECC than seen in Figure 2B. Hence, although we present a logistic model to estimate the relative position of elk with respect to ECC based on BF of lactating cows, we caution managers to pay greater attention to critical thresholds (i.e., $>14 \%=$ no relevant nutritional stress; $<7.9 \%=$ strong nutritional stress) rather than proportion of ECC until BF dynamics at very low levels of nutrition are clarified.

Use of $\mathrm{BF}$ to assess degree of habitat limitation or proximity to ECC is much more sensitive than previous work, which used the instantaneous rate of population increase $(r)$ to define population-ECC relations (Fowler 1981, 1988; Eberhardt 1987). Use of population rate of increase necessitates inclusion of population characteristics such as fecundity and survival of juveniles and adults, each of which show different response times to resource stress (Gaillard et al. 2000), and some of which, such as adult survival, are very insensitive to resource stress (Gaillard et al. 2000; Eberhardt 2002). Thus, significant habitat degradation needs to have already occurred before a response in population rate of increase can be observed. Conversely, because BF is a direct result of energy acquisition, it is extremely sensitive to even slight changes in resource quality (Cook et al. 2004) and consequently responds almost immediately to changes in habitat quality (Hanks 1981; Fig. 2). Thus, modeling elk-habitat relations using BF provides managers with a much more sensitive tool than previous attempts to detect population-habitat relationships and changes in habitat quality using population demographics, changes that may not occur for $\geq 1 \mathrm{yr}$ following even significant declines in habitat quality (Gaillard et al. 2000; Eberhardt 2002).

Further, ECC is usually framed in the context of animal densities and density dependence; however, populations can vary with respect to nutritional condition and consequently ECC regardless of density. For example, in the case of a drought that lowers forage quality below maintenance values required by elk, no one animal on that range could meet its nutritional requirements, no matter how many other elk were sharing that range. In this case, even one animal using that range would be exceeding the ECC for elk. At the same time, quantity of forage may be sufficient to preclude competition, and thus the range could have greater numbers of elk present without any difference seen in condition, which would be uniformly low. Hence, managers should not assume that only density-dependent factors affect elk condition and elk-ECC relationships (Bender and Cook 2005).

To illustrate the preceding points, the proportion of cows lactating in our population-years, an index of successful production of a calf through autumn, was negatively $(r=-0.51)$ related to proportion of ECC. However, this relationship was not particularly strong $\left(R^{2}=0.26\right)$ because the predominant influences on preweaning calf survival are density-independent (i.e., factors not related to maternal condition, such as accidents, weather, etc; Clutton-Brock 1982; Clutton-Brock and Coulson 2002). This illustrates the insensitivity of using the components of rate of increase to assess habitat quality or demographic vigor of a population (Hanks 1981; Eberhardt 2002), because these components (i.e., fecundity, survival rates, etc.) are removed from the direct habitat-condition link. Further, because poor condition can affect pregnancy rates (Cook et al. 2004; Piasecke 2006), consequences of close proximity to ECC may not be reflected until the following season or seasons. For example, elk in CCNHP increased to $97 \%$ of ECC in 2005 after ranging from $13 \%$ to $52 \%$ ECC from 2003 to 2004 (Table 4), with the decline in condition of elk resulting from low precipitation in the late gestation-early lactation period (Bender 2007), not density-dependence (elk density increased only from 0.13 elk $\cdot \mathrm{km}^{-2}$ to $0.15 \mathrm{elk} \cdot \mathrm{km}^{-2}$ and was unrelated to condition; Bender 2007). However, calf recruitment did not decline until the following year $(2006=0.30$ vs. 0.65 for 2003-2005; Fischer's exact $P=0.004$ ) in response to the decline in condition first seen in 2005. This illustrates how body condition of individuals is affected first and in a very sensitive manner with increasing resource stress, whereas time lags can 
result in fecundity and survival not being affected until much later (Hanks 1981; Gaillard et al. 2000; Eberhardt 2002). Thus, even such a dramatic decrease in habitat quality may not be reflected in changes in population demographics for $\geq 1 \mathrm{yr}$, whereas monitoring of $\mathrm{BF}$ revealed this decline immediately.

Using the logistic model, population-years ranged throughout our study from $3 \%$ to $97 \%$ of ECC. According to categories of nutrition delineated for penned elk, most of our populationyears experienced poor-marginal nutrition (BF of lactating adults $<12 \%$ ); only two accrued $12-13 \% \mathrm{BF}$, at the low end of good $(12-16 \%)$ nutrition; and none achieved excellent $(>16 \%$ BF; Cook et al. 2004). Because population-years were as low as $3 \%$ ECC, this suggests that criteria used to designate those categories may be pessimistic for free-ranging elk. However, despite designating a criterion for no relevant nutritional limitation (approximately 14\% BF for lactating cows) that is lower than nutritional studies of penned elk would suggest, none of our populations were able to reach this level of condition, indicating that extant habitat conditions for many elk populations are limiting elk condition to some degree and are likely related to declining productivity seen in many areas of the West (Gratson and Zager 1999; Noyes et al. 2002; Rearden 2005).

Last, the relationship between $\mathrm{BF}$ and proximity of an elk population to ECC resulted from the importance of BF as an endogenous reserve and hence its direct link to habitat quality and population performance (Clutton-Brock et al. 1982; Cook et al. 2004; Bender and Cook 2005), and was consequently very sensitive to annual and even seasonal changes in habitat quality. However, condition must be estimated at or near the annual peak, i.e., just before the onset of forage senescence in late autumn, because the relationship is based on what the habitat is capable of allowing elk to achieve. Estimating condition at other times may result in lower condition and thus an underestimate of habitat quality. Further, although we used live animal measures to estimate BF, numerous dead animal indices are available to estimate BF from harvested elk (Cook 2000; Cook et al. 2001a, 2001b). Because hunting seasons for elk typically occur in late autumn or early winter when BF is at or near annual peaks, managers can use measures from harvested individuals to estimate condition of lactating cows in populations and thus compare populations against thresholds described above.

\section{MANAGEMENT IMPLICATIONS}

By measuring BF of lactating cows in autumn, managers can define how close elk populations are to important biological thresholds for elk management. Because BF affects the likelihood of a cow conceiving (Cook et al. 2004; Piasecke 2006) and its calf surviving (Clutton-Brock et al. 1982; Cook et al. 2004), models of elk-habitat relations based on BF have direct implications for predicting population performance as well. If lactating cows average $\geq 14 \% \mathrm{BF}$, there should be no intrinsic constraints on reproduction, although density-independent effects could still affect total recruitment by lowering calf survival (Clutton-Brock 1982; Clutton-Brock and Coulson 2002; Piasecke 2006). Below 14\% BF elk move away from approximately $0 \%$ of ECC and nutritional limitations may begin to lower population performance. If lactating cows average $\leq 7.9 \% \mathrm{BF}$, the population is likely experiencing strong nutritional stress and density-dependent or other factors limiting resource quality are likely limiting population performance (Eberhardt 1987). If these effects are density dependent, increasing elk harvest rate could lower elk density, improve body condition, and generate compensatory productivity. However, managers should be aware that density-independent factors such as drought or inherently poor forage quality can also lower elk condition independent of density effects. Because levels of BF accrued by elk in autumn are predominately a result of the nutritional quality of spring-autumn ranges (Cook et al. 2004, Piasecke 2006), monitoring elk BF can also allow managers to detect how successful current habitat management practices are for elk and whether investment in habitat improvements is warranted.

\section{ACKNOWLEDGMENTS}

We thank J. Cook, R. Cook, B. Hall, H. Halbritter, B. Hoenes, J. Hagerman, and E. Watters for assistance in field activities.

\section{LITERATURE CITED}

Bayliss, P., and D. Choquenot. 2003. The numerical response: rate of increase and food limitation in herbivores and predators. In: R. M. Sibly, J. Hone, and T. H. Clutton-Brock [EDS.]. Wildlife population growth rates. Cambridge, United Kingdom: University Press. p. 148-179.

Bender, L. C. [COMPILER]. 2007. Growth, health, and impacts of a pioneering elk herd on and adjacent to Chaco Culture National Historic Park, New Mexico. Las Cruces, New Mexico, USA: New Mexico Cooperative Fish and Wildlife Research Unit. Final Report. $126 \mathrm{p}$.

Bender, L. C., E. Carlson, S. M. Schmitt, and J. B. Haufler. 2002. Production and survival of elk (Cervus elaphus) calves in Michigan. American Midland Naturalist 148:163-171.

Bender, L. C., AND J. G. Cook. 2005. Nutritional condition of elk in Rocky Mountain National Park. Western North American Naturalist 65:329-334.

Bender, L. C., J. G. Cook, R. C. Cook, and P. B. Hall. 2008. Relationships between nutritional condition and survival of North American elk Cervus elaphus. Wildlife Biology 14:70-80.

Bender, L. C., M. A. Davison, J. G. Cook, R. C. Cook, and P. B. Hall. 2006. Assessing elk population status and potential performance in the Nooksack area, Washington. Northwestern Naturalist 87:98-106.

Burnham, K. P., and D. R. Anderson. 1998. Model selection and inference: a practical information-theoretic approach. New York, NY, USA: SpringerVerlag. 353 p.

Carpenter, L. H. 2000. Harvest management goals. In: S. Demarais and P. R. Krausman [EDS.]. Ecology and management of large mammals in North America. Upper Saddle River, NJ, USA: Prentice Hall. p. 192-213.

Caughley, G. 1979. What is this thing called carrying capacity? In: M. S. Boyce and L. D. Hayden-Wing [EDS.]. North American elk: ecology, behaviour, and management. Laramie, WY, USA: University of Wyoming Press. p. 2-8.

Clutton-Brock, T. H., And T. Coulson. 2002. Comparative ungulate dynamics: the devil is in the detail. Philosophical Transactions of the Royal Society of London 357:1285-1298.

Clutton-Brock, T. H., F. E. Guinness, and S. D. Albon. 1982. Red deer: behavior and ecology of two sexes. Chicago, IL, USA: University of Chicago Press. 378 p.

Cook, J. G. 2002. Nutrition and food. In: D. E. Toweill and J. W. Thomas [EDS.]. North American elk: ecology and management. Washington, DC, USA: Smithsonian Institution Press. p. 259-349.

Cook, J. G., B. K. Johnson, R. C. Cook, R. A. Riggs, T. Delcurto, L. D. Bryant, and L. L. IRWIN. 2004. Effects of summer-autumn nutrition and parturition date on reproduction and survival of elk. Wildlife Monographs 155:1-61. 
Cook, R. C. 2000. Studies of body condition and reproductive physiology in Rocky Mountain elk [thesis]. Moscow, ID, USA: University of Idaho. 117 p.

Cook, R. C., J. G. Cook, D. L. Murray, P. Zager, B. K. Johnson, and M. W. Gratson. 2001a. Development of predictive models of nutritional condition for Rocky Mountain elk. Journal of Wildlife Management 65:973-987.

Cook, R. C., J. G. Cook, D. L. Murray, P. Zager, B. K. Johnson, and M. W. Gratson. 2001b. Nutritional condition models for elk: which are the most sensitive, accurate, and precise? Journal of Wildlife Management 65:988-997.

Depperschmidt, J. D., S. C. Torbit, A. W. Alldredge, and R. D. Deblinger. 1987. Body condition indices for starved pronghorns. Journal of Wildlife Management $51: 675-678$.

Eberhardt, L. L. 1987. Population projections from simple models. Journal of Applied Ecology 24:103-118.

Eberhardt, L. L. 2002. A paradigm for population analysis of long-lived vertebrates. Ecology 83:2841-2854.

Eberhardt, L. L. 2003. What should we do about hypothesis testing? Journal of Wildlife Management 67:241-247.

Festa-Bianchet, M., J.-M. Gaillard, and J. T. Jorgenson. 1998. Mass- and densitydependent reproductive success and reproductive costs in a capital breeder. American Naturalist 152:367-379.

FoWLER, C. W. 1981. Density dependence as related to life history strategy. Ecology 62:602-610

Fowlen, C. W. 1988. Population dynamics as related to rate of increase per generation. Evolutionary Ecology 2:197-204.

Gaillard, J.-M., M. Festa-Bianchet, N. G. Yoccoz, A. Loison, and C. Toïgo. 2000. Temporal variation in fitness components and population dynamics of large herbivores. Annual Review of Ecology and Systematics 31:367-393.

Gratson, M. W., and P. ZaGer. 1999. Elk ecology study IV: factors influencing elk calf recruitment. Boise, ID, USA: Idaho Department of Fish and Game. Job progress report. Pittman-Robertson Project W-160-R-25 subproject 31. 22 p.

Gray, P. B., and F. A. Servello. 1995. Energy intake relationships for white-tailed deer on winter browse diets. Journal of Wildlife Management 59:147-152.

HanKS, J. 1981. Characterization of population condition. In: C. W. Fowler and T. D. Smith [EDS.]. Dynamics of large mammal populations. New York, NY, USA: John Wiley and Sons. p. 47-73.
Hofmann, R. R. 1989. Evolutionary steps of ecophysiological adaptation and diversification of ruminants: a comparative view of their digestive system. Oecologia 78:443-457.

Holechek, J. L., R. D. Pieper, and C. H. Herbel. 2004. Range management: principles and practices. 5th ed. Upper Saddle River, NJ, USA: Pearson-Prentice Hall. $607 \mathrm{p}$.

Hudson, R. J., J. C. Haigh, and A. B. Bubenik. 2002. Physical and physiological adaptations. In: D. E. Toweill and J. W. Thomas [EDS.]. North American elk: ecology and management. Washington, DC, USA: Smithsonian Institution Press. p. 199-257.

Kistner, T. P., K. R. Greer, D. E. Worley, and 0. A. Brunetti. 1982. Diseases and parasites. In: J. W. Thomas and D. E. Toweill [EDS.]. Elk of North America: ecology and management. Harrisburgh, PA, USA: Stackpole Books. p. 181-217.

Landete-Castillejos, T., A García, J. A. Gómez, and L. Gallego. 2003. Lactation under food constraints in Iberian red deer Cervus elaphus hispanicus. Wildlife Biology 9:131-139.

Noyes, J. H., B. K. Johnson, B. L. Dick, And J. G. Kie. 2002. Effects of male age and female nutritional condition on elk reproduction. Journal of Wildlife Management 66:1301-1307.

PIASECKE, J. R. 2006. Relationships among condition, health, and reproduction in free-ranging elk (Cervus elaphus) populations throughout the United States [thesis]. Las Cruces, NM, USA: New Mexico State University. 234 p.

REARDEN, S. 2005. Elk calf survival in northeastern Oregon: preliminary results. Northwestern Naturalist 86:113.

SinclaiR, A. R. E. 1977. The African buffalo: a study of resource limitation of populations. Chicago, IL, USA: University of Chicago Press. $355 \mathrm{p}$.

TraineR, C. E. 1969. Fertility study of Roosevelt elk. Corvallis, OR, USA: Oregon Department of Fish and Wildlife. Job completion report. Pittman-Robertson Federal Aid Project W-59-R-06. Job 06. $25 \mathrm{p}$.

Wickstrom, M. L., C. T. Robbins, T. A. Hanley, D. E. Spalinger, and S. M. Parish. 1984. Food intake and foraging energetics of elk and mule deer. Journal of Wildlife Management 48:1285-1301.

ZAR, J. H. 1996. Biostatistical analysis. 3rd ed. Upper Saddle River, NJ, USA: Prentice Hall. 662 p. 